\title{
MÉDIA, GÉNERO E DIREITOS HUMANOS: DIÁLOGOS (IM)POSSÍVEIS
}

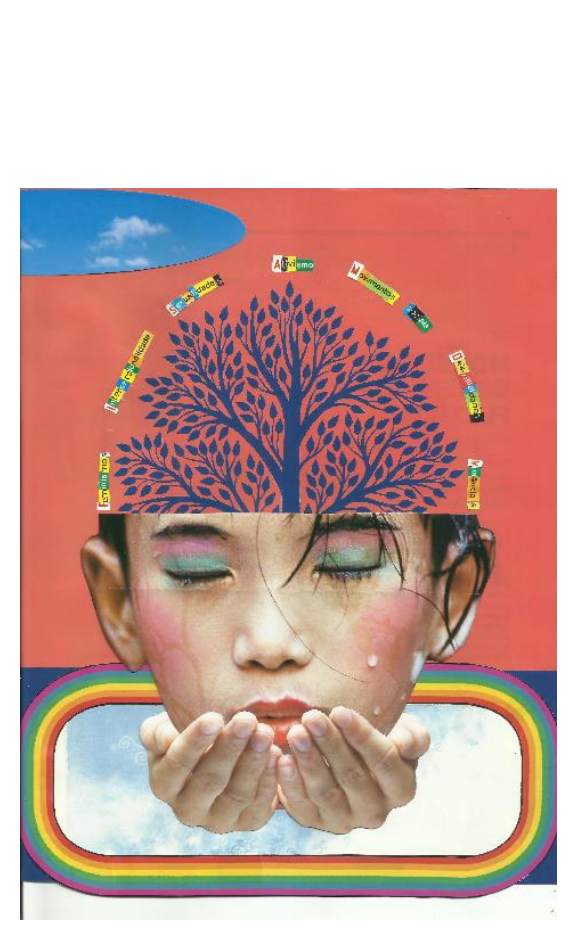

Carla Cerqueira ${ }^{1}$

Anabela Santos ${ }^{2}$

Paper collage: Ariana Mei (Portugal)

Os média assumem um papel central enquanto (in)formadores da opinião pública, constituindo "lugares sociais e políticos de construção de identidades" (Silveirinha, 2004: 9). São dos mais importantes agentes de socialização, influenciando aquilo que se pensa e como se age individual e coletivamente. Neste sentido, a atenção que tem sido prestada aos média e à relação destes com as (des)igualdades de género e os direitos humanos já não é recente, tendo tido o seu início nas décadas de 1960 e de 1970 (Cerqueira

\footnotetext{
${ }^{1}$ Doutorada em Ciências da Comunicação pela Universidade do Minho, Portugal. Atualmente é bolseira de pós-doutoramento em Ciências da Comunicação da Fundação para a Ciência e a Tecnologia (SFRH/BPD/86198/2012), investigadora do Centro de Estudos de Comunicação e Sociedade (CECS), da Universidade do Minho, e professora auxiliar na Universidade Lusófona do Porto, Portugal.

${ }^{2}$ Bolseira de doutoramento da Fundação para a Ciência e a Tecnologia (PD/BD/105928/2014), frequentando atualmente o Programa Doutoral FCT em "Estudos de Comunicação: Tecnologia, Cultura e Sociedade" (Universidade do Minho).
} 


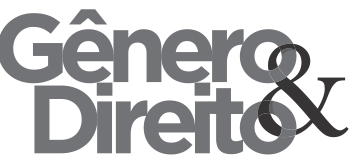

\& Cabecinhas, 2012). Desde essa altura até à atualidade, houve mudanças substanciais nas relações de género, no ativismo feminista, no campo mediático e na sociedade em geral (Byerly, 2013; Carter, Steiner \& McLaughlin, 2015; Gallagher, 2014; Gallego, 2013; Krijnen, Álvares \& Van Bauwel, 2011; Krijnen \& Van Bauwel, 2015; Lobo, Silveirinha, Subtil, \& Torres, 2015; Ross, 2009; Silveirinha, 2001; Van Zoonen, 1994, 2010, in Cerqueira, Magalhães \& Cabecinhas, 2016: 5).

O campo de investigação em torno dos média, género e direitos humanos encontra-se hoje em franca expansão a nível (inter)nacional, sendo marcado por várias tensões e por uma complexidade cada vez maior (Van Zoonen, 2010). Parece-nos, pois, necessário contribuir para o aprofundamento da reflexão crítica e politicamente comprometida, sobretudo numa altura em que os média fazem parte dos muitos eixos do neoliberalismo, as "lutas no campo do género continuam" (Silva et al, 2017: 14), as relações de poder e as hierarquias (simbólicas) se cristalizam, os discursos de ódio adquirem
Periódico do Núcleo de Estudos e Pesquisas sobre Gênero e Direito

Centro de Ciências Jurídicas - Universidade Federal da Paraíba

V. 6 - No 01 - Ano 2017 - Mídia, Gênero \& Direitos Humanos ISSN | 2179-7137 | http://periodicos.ufpb.br/ojs2/index.php/ged/index

legitimidade pública e os direitos conquistados são alvo de retrocessos.

Esta edição especial da revista Gênero \& Direito é dedicada à temática Mídia, Gênero \& Direitos Humanos e parte da necessidade de se fomentar um debate conjunto sobre temas diversos mas que se cruzam no âmbito dos estudos feministas dos média. Composta por contributos provenientes do contexto brasileiro e português, esta publicação abarca diferentes posicionamentos teóricos, metodológicos e empíricos. São várias as plataformas mediáticas analisadas, bem como é transversal uma preocupação em atentar na esfera da produção, dos conteúdos e da receção, seguindo uma linha já vigente na academia internacional (Cerqueira et al, 2014; Krijnen \& Van Bauwel, 2015).

Diálogos (im)possíveis parece uma boa designação para o leque de trabalhos que encontramos nesta edição especial, um vez que "os media têm um enraizamento paradoxal na experiência simbólica", apresentando-se quer como "dispositivos de administração e controlo", quer como plataformas de "resistência social" (Esteves, 2003: 93). 
A edição tem início com o artigo A violência contra as mulheres como uma violação dos direitos humanos: do positivado ao noticiado, da autoria de Brenda Fernandes e de Carla Cerqueira, que apresenta um estudo exploratório sobre o Brasil e Portugal no sentido de compreender o modo como os média abordam a violência contra as mulheres, nomeadamente quando estas são figuras públicas. A análise realizada permite concluir que os média não tratam a violência contra as mulheres como uma violação dos direitos humanos, optando, ao invés, por representá-la como uma situação isolada, pontual e desprovida de um caráter ideológico.

\section{As investigadoras Ariana}

Pinto Correia, Sofia Neves, Sílvia Gomes e Conceição Nogueira em O femicídio na intimidade sob o olhar dos media: reflexões teóricoempíricas apresentam uma revisão crítica da literatura sobre a cobertura noticiosa do femicídio, sendo este encarado como uma das mais graves formas de violência de género. As autoras apontam para a necessidade de se investir na literacia crítica para os
Periódico do Núcleo de Estudos e Pesquisas sobre Gênero e Direito

Centro de Ciências Jurídicas - Universidade Federal da Paraíba

V. 6 - Nº 01 - Ano 2017 - Mídia, Gênero \& Direitos Humanos ISSN | 2179-7137 | http://periodicos.ufpb.br/ojs2/index.php/ged/index

média no sentido de potenciar um entendimento sobre a ideologia de género que está na base e sustenta a violência contra as mulheres.

\section{Em Pensar o Género na} publicidade: percepções de estudantes do ensino superior português, Ana Reis Jorge, Carla Cerqueira e Sara I. Magalhães discutem os resultados do projeto PubliDiversidade, focado na análise das representações de género na publicidade. Através da realização de grupos focais, analisam as percepções de jovens universitárias/os da área de comunicação relativamente à dimensão de género na publicidade, enfatizando as estratégias de auto e heteroregulação existentes. Concluem com a necessidade de ampliação de uma literacia publicitária crítica, pautada pela promoção da igualdade de género.

No artigo De Healer à Commando: Estereótipos de género na construção das personagens femininas em Final Fantasy XIII, Luísa Kaanan apresenta uma análise a partir de 50 horas de jogo, com apoio de sites oficiais, de fãs e do manual do jogo. A autora chega à conclusão que as personagens femininas tendem a ser 


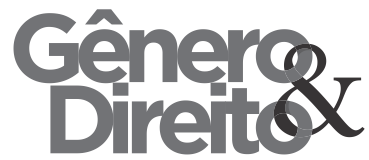

construídas a partir das categorias sexuais, refletindo estereótipos e papéis de género tradicionais.

Letícia Sarturi Isaia e Carla Cerqueira no artigo Mulheres, empoderamento e autoestima: a influência dos blogs de moda na identidade Plus Size focam-se neste tipo específico de blogs, nomeadamente "Entre Topetes e Vinis", do Brasil, e "GabiFresh", dos EUA, de forma a perceber os laços existentes entre $\mathrm{o}$ corpo das mulheres e a moda na promoção da identidade plus size. Da análise concluem, entre outros aspetos, que estes funcionam como pontos de resistência diante do mainstream que fomenta determinados padrões estéticos e exclui e/ou secundariza outros, sobretudo no que concerne ao corpo das mulheres.

\section{Em Género e jornalismo} parlamentar em Portugal, Carla Baptista parte de entrevistas a repórteres parlamentares e deputadas portuguesas, realizadas no âmbito do projeto Política no Feminino: Políticas de Género e Estratégias de Visibilidade das Deputadas Parlamentares, para analisar os défices ao nível da participação de mulheres e de temáticas
Periódico do Núcleo de Estudos e Pesquisas sobre Gênero e Direito

Centro de Ciências Jurídicas - Universidade Federal da Paraíba

V. 6 - Nº 01 - Ano 2017 - Mídia, Gênero \& Direitos Humanos ISSN | 2179-7137 | http://periodicos.ufpb.br/ojs2/index.php/ged/index

relacionadas com o género na cobertura jornalística do Parlamento em Portugal. Das conclusões ressalta o desinteresse dos/as jornalistas parlamentares pela cobertura de iniciativas legislativas sobre políticas de género.

A fechar a edição especial, Sara Moreira, Sara I. Magalhães e Conceição Nogueira assinam o artigo Contornar e Contorcer(-se): Contorcionismos na objetificação das mulheres em contexto político pelos média portugueses, no qual analisam as representações jornalísticas de mulheres que exercem cargo políticos, auscultando os mecanismos de objetificação acionados nas narrativas do seminário português Expresso. Os resultados mostram que prevalecem representações genderizadas, essencialistas e pouco inclusivas, sendo que a despersonalização surgiu como o mecanismo mais recorrente de objetificação das mulheres que exercem cargos políticos.

$\mathrm{Na}$ secção livre, Eduardo R. Rabenhorst reflecte sobre Visibilidade e Direito: Esboço de um problema. O autor traça um esboço de investigação sobre a relação entre cultura visual e direito, focando na necessidade de reconhecimento social e jurídico de 


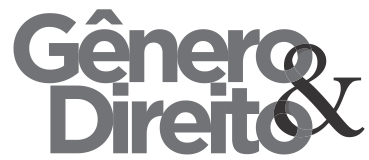

grupos considerados minoritários ou vulneráveis.

No que concerne à secção de resenhas, esta edição tem início com um texto de Nuno Santos Carneiro sobre o livro ¡Divinas! Modelos, Poder y Mentiras, de Patrícia Soley-Beltran (2015). De seguida, Maria Helena Santos resenha o livro Mulheres, Liderança Política e Media (2015), de Carla Martins. A fechar a edição, Rui Vieira Cruz apresenta uma resenha da obra Slutwalk, Feminism, Activism and Media, da autoria de Kaitlynn Mendes (2015).

\section{Referências bibliográficas}

Cerqueira, C. \& Cabecinhas, R. (2012). Políticas para a igualdade entre homens e mulheres nos media: da (inov)ação legislativa à mudança social. Ex Aequo, 25: 105-118.

URL: http://www.scielo.mec.pt/scielo.php?sc ript=sci_arttext\&pid=S087455602012000100009.

Cerqueira, C.; Magalhães, S. I.; Santos, A.; Cabecinhas, R. \& Nogueira, C. (2014). De outro género: Propostas para a promoção de um jornalismo mais inclusivo. Braga: CECS. URL:
Periódico do Núcleo de Estudos e Pesquisas sobre Gênero e Direito

Centro de Ciências Jurídicas - Universidade Federal da Paraíba

V. 6 - No 01 - Ano 2017 - Mídia, Gênero \& Direitos Humanos ISSN | 2179-7137 | http://periodicos.ufpb.br/ojs2/index.php/ged/index

http://www.lasics.uminho.pt/ojs/index. php/cecs_ebooks/issue/view/156/show

Toc.

Cerqueira, C.; Cabecinhas, R. \& Magalhães, S. I. (2016). Gender and media: where do we stand today? In C. Cerqueira; R. Cabecinhas \& S. I. Magalhães (Eds.), Gender in focus: (new) trends in media (pp. 5-11). Braga: CECS.

URL:

http://www.lasics.uminho.pt/ojs/index. php/cecs_ebooks/article/view/2335/22 $\underline{51 .}$

Esteves, J. P. (2003) Espaço público e democracia. Lisboa: Edições Colibri. Krijnen, van Bauwel. S. (2015). Gender and Media: Representing, Producing, Consuming. London and New York: Routledge.

Silva, M. C.: Lima, L.; Sobral, J. M.; Araújo, H. \& Ribeiro, F. B. (2016). Introdução, estratégias de pesquisa e síntese dos contributos. In M. C. Silva; M. L. Lima; J. M. Sobral; H. Araújo \& F. B. Ribeiro (Eds.). Desigualdades e Políticas de Género (pp. 9-24). V. N. Famalicão: Húmus. 


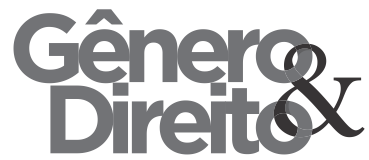

Periódico do Núcleo de Estudos e Pesquisas sobre Gênero e Direito

Centro de Ciências Jurídicas - Universidade Federal da Paraíba

V. 6 - No 01 - Ano 2017 - Mídia, Gênero \& Direitos Humanos

ISSN | 2179-7137 | http://periodicos.ufpb.br/ojs2/index.php/ged/index

Silveirinha, M. J. (2004).

'Representadas e representantes: as mulheres e os media'. Revista Media \& Jornalismo, As mulheres e os media, 5, (3): 9-30.

Van Zoonen, L. (2010). 'Preface'. In, T.

Krijnen; C. Álvares \& S. Van Bauwel.

(Eds.), Gendered Transformations.

Theory and Practices on Gender and

Media (pp.1-8). Bristol: Intellect. 